\title{
A REDE E O CONHECIMENTO
}

\section{Plácida L. V. Amorim da Costa Santos Vinício Carrilho Martinez}

\section{Resumo}

No futuro, com a crescente virtualização (tecnologia substituindo o espaço público da prática política), é que se mostrará se a democracia foi posta em rede (pública) ou se apenas foi "tecnologizada", tornando-se a imagem mais cara do conceito, ou seja, "publicidade". A articulação da idéia de rede com a experiência das bibliotecas públicas seria uma possibilidade na realização da interação social e na construção da cidadania

\section{Palavras-Chave}

Democracia; Rede; Informação; Bibliotecas Públicas. 
Não se discute a utilidade da Internet, mas seus projetos

Destacamos a idéia de rede como sendo a que abrange a formação do conhecimento a partir das relações sociais, como uma teia de relações que não se inicia em uma estrutura linear ou mesmo acadêmica, a exemplo da apresentada atualmente pela escola ou pelas bibliotecas tradicionais. A articulação da idéia de rede com a experiência das bibliotecas públicas como o meio mais adequado para a difusão das informações é fundamental do ponto de vista da formação da cidadania, por outro aspecto, entendemos que, primeiro, sem acesso à informação o indivíduo-eleitor não passa à condição de cidadão consciente e, segundo, que a raiz da democracia no nível da informação está na capacidade ampliada da produção livre e aberta de novas mensagens. Mas, inversamente, não há como falar de produção democrática de novas mensagens sem que haja uma real democratização dos meios de informação.

É importante frisar que as eleições eletrônicas de 96 são um marco desta realidade político-tecnológica (um marco cultural), ressaltando a necessidade do debate sobre a Educação Política Popular (plebiscito, referendo, iniciativa popular, etc.), para conhecer e melhor praticar os instrumentos políticos disponíveis ao eleitorgovernante. Por outro lado, também se verifica a necessidade de uma Educação Tecnológica, na medida em que a democracia passa a ser conectada em rede (elei- ções eletrônicas em 96, etc.). Pois, uma vez colocada a política no plano virtual, exigese dos formuladores das mensagens políticas e dos participantes do jogo democrático uma reorientação não apenas para o voto eletrônico deste ano, mas para o dos futuros.

Com isso, ressaltamos um primeiro problema: os instrumentos políticos tradicionais estão equipados para abordar a cultura provinda dos "meios tecnológicos"? No que consiste esta realidade da prática política virtual?

O que remete a um problema de fundo: têm-se em vista as garantias sociais de que todo cidadão pode participar ativamente da formulação dos conteúdos políticos (cidadania ativa) a serem veiculados (em rede), mas como fazer uso dos meios técnicos como se fazia, por exemplo, com as grandes manifestações em praça pública?

Do que decorre outra questão: será possível a efetivação democrática da rede mesmo sob a égide do liberalismo, expresso no uso individualista dos equipamentos?

Daí que as garantias tecnológicas da democracia aparecem na condicional. Porque somente no futuro, com a crescente virtualização (tecnologia substituindo o espaço público da prática política), é que veremos se a democracia foi posta em rede (pública) ou se apenas foi "tecnologizada", tornando a imagem mais cara do que o conInf.Inf., Londrina, v. 5, n. 2, p. 111-124, jul./dez. 2000 
ceito (publicidade).

No entanto, entendemos que a relação entre democracia e rede seja possível porque há princípios intercomunicantes entre as duas realidades sociais, tais como: a noção de pluralidade, a difusão "radial" das experiências sociais próprias às duas dimensões, a profusão de valores centrais à cidadania, etc.

A idéia da rede democrática foi priorizada por dois motivos. Primeiro, porque são conceitos e práticas que melhor sintetizam as experiências mais globais. $\mathrm{E}$, segundo, porque nem sempre a democracia é plena (ou está em rede) e nem sempre a rede está disposta de forma democrática ${ }^{1}$. Um exemplo claro é o acesso às experiências da rede nem sempre ser democrático, como todos os tipos de serviços on line que custam caro ao consumidorusuário e com isso restringem sua utilização - como o caso dos pequenos partidos políticos que não têm acesso à tecnologia.

Por outro lado, a idéia de rede como verdadeiro aporte social ou comunitário não é nova. Pode-se dizer que a idéia do pescador que serve a toda a comunidade, fazendo uso de sua rede, é bíblica. Mas no sentido moderno da expressão, em que se toma a Internet como exemplo mais característico, a relação política é ainda mais

${ }^{1}$ Tome-se o exemplo da eleição de Fernando Collor de Melo para presidente, quando o mais importante era o show da tecnologia, veiculado em propagandas políticas gratuitas, e não o debate político sobre as forças políticas alí representadas. evidente (sabe-se que a Internet já foi um projeto militar antes de chegar às universidades $^{2}$ ).

Em sentido amplo, porém, a rede Internet, como instrumento que pode contribuir para o fenômeno de integração econômica mundial, nos conduz à reflexão sobre o papel das bibliotecas públicas dos países envolvidos em acordos econômicos e sociais.

Tem-se difundido a tese de que a Internet vem-se constituindo um "novo espaço público". Para alguns, no entanto, a tese é privatista. Porque, desligando-se momentaneamente como usuário do sistema "pretensamente interativo", o indivíduo volta-se ao ambiente do escritório ou ao quarto de dormir. Nesse caso, é oportuno relembrar a crítica do chamado "technological fix", que alimentou o surgimento da Ciência da Informação com os conhecimentos tecnológicos da informática, sobretudo no pós - $2^{\mathrm{a}}$ Guerra, pela atenção excessiva que era dada à tecnologia. De acordo com Furnival (1995, p.16), o foco "deve ser mudado para a informação, e não a tecnologia usada para manipulá-la: em outras palavras, o 'technological fix' nem sempre constitui a

${ }^{2}$ Têm-se difundido a tese de que a Internet vem-se constituindo um "novo espaço público". Mas, se não houver nenhum anteparo social, já nasceu "privatizado". Porque, desligando-se momentaneamente como usuário do sistema "pretensamente interativo", o indivíduo volta-se ao ambiente do escritório ou ao quarto de dormir. Seria, nesse caso, o melhor exemplo de um "novo espaço público" nascido sob a égide do privado, ou da "colonização do público pelo privado". 
melhor solução".

As bibliotecas públicas, como espaços públicos tradicionais e agentes catalisadores da cultura da comunidade na qual estão inseridas precisam ser utilizadas como instrumentos para a construção e apropriação coletiva do conhecimento, atuando como um nó em uma rede que possibilite a interação e integração política, social, tecnológica e mesmo individual, contribuindo assim para o desenvolvimento de um amplo plano social.

A instituição biblioteca, como responsável pela preservação, estocagem e disseminação da produção intelectual do homem, constitui-se recurso fundamental para o desenvolvimento social, político, cultural e econômico dos povos. Assim, com a rede Internet, bibliotecas deverão reestruturar suas formas de atuação no sentido de facilitar a aproximação e o acesso à informação. O bibliotecário - como sujeito institucional, neste momento histórico social - deve aproveitar as vantagens da chegada da era da informação e estabelecer-se na gestão moderna das unidades de informação, como têm feito muitos profissionais.

Neste ambiente multidisciplinar em que hoje se desenvolvem as tarefas de informação, o bibliotecário tem a vantagem intelectual de ser o que melhor conhece a essência dos processos de análise, descrição e armazenamento informacional e documentário. Mas tem, entretanto, que estar apto para apropriar-se das ferramentas tecnológicas disponíveis para aperfeiçoamento e agilização de processos decisivos para o estabelecimento de bibliotecas bem gerenciadas e que considerem as metodologias atuais de administração e gestão de recursos humanos e materiais. Essas instituições têm como objetivo de trabalho o usuário, no centro do sistema, e ao seu redor todos os processos encaminhados para resolver sua demanda informativa e, por sua vez, o estímulo ao surgimento de nova demanda. Como indicam Mercier, Plassard \& Scardigli (1985, p.20),

\section{"Os chips eletrônicos estão inva- dindo nossa vida cotidiana, e sua fecundidade se anuncia fulmi- nante. Nestes momentos só nos surpreendem ou irritam. Porque estão vazios, porque carecem de sentido. O único problema con- siste em saber que...<alma $>$ lhes estamos dando" (tradução livre).}

O que Mercier denomina por "alma" pode ser chamado de "projeto social" ou até mesmo de "valor de uso político". De qualquer forma, vê-se que se trata de uma realidade exterior aos princípios do mero aplicativo da técnica e exige uma discussão da própria tecnologia a partir do a priori político, uma constante em toda relação humana, seja ela com outros homens seja com algum equipamento.

Nesse sentido, o papel do profissional da informação é essencial, porquanto os recentes avanços tecnológicos nas áre- 
as de informática e de comunicação estão transformando o mundo e agregando valor à informação disponibilizada de forma universalmente acessível.

Durante séculos o conceito de biblioteca prendeu-se à imagem de um organismo estático, destinado à conservação documental e seus objetivos fundamentais centravam-se apenas em reunir, selecionar, catalogar, classificar e colocar à disposição dos leitores os materiais fisicamente disponíveis.

Entretanto, apesar do rastro estereotipado deixado pela biblioteca pública, é ela a instituição social capaz de proporcionar a todos o livre acesso aos registros do conhecimento e das idéias do homem. Em suma: as expressões de sua imaginação criadora. É ela que oferece a oportunidade da democratização da vida cultural, por meio do acesso aos bens culturais, através da disponibilização do conhecimento registrado. Sua condição de provedora de informação permite ao homem o acesso aos diversos discursos sociais, propiciando a participação ativa de cada sujeito psicossocial no desenvolvimento sócio-político-cultural. tervir na formação de suas próprias subjetividades. Seu sucesso, porém, depende de sua adequação ao novo paradigma de comunicação e às novas necessidades de seus usuários.

As bibliotecas públicas, fazendo uso das novas tecnologias e de modo especial da rede Internet, poderão contribuir para a efetiva integração mundial, visto que somente a queda de barreiras alfandegárias não será suficiente para a integração dos povos.

À biblioteca pública compete encarar de frente os desafios da globalização, uma vez que é esta a instituição que possui como peculiaridade a internacionalidade da disseminação do conhecimento, por meio da cooperação e intercâmbio da informação. Como instituições sociais, estas bibliotecas, servindo-se das novas tecnologias em informação e da utilização de ferramentas como a rede Internet, poderão desempenhar ações decisivas para a efetivação da integração social. Grover (1995, p. 7) descreve com muita propriedade as necessidades das sociedades e dos sujeitos na atualidade,
A condição atual impõe à instituição biblioteca pública problemas e desafios bastante concretos e ela não pode ficar à margem das questões contemporâneas por suas implicações com a disseminação do conhecimento registrado, pois as bibliotecas são instituições sociais que favorecem a ampliação da capacidade humana de in- "quando um sistema de cooperação é estabelecido, devemos abandonar o tradicional modo de pensar de um bibliotecário e perceber que o usuário não está procurando um livro ou artigo, mas sim informação."

Ao citarmos Grover, queremos desta- 
car que a intenção de um projeto de cooperação entre bibliotecas públicas via Internet reside no desencadear de um processo de relações institucionais, tecno-científicas e pessoais. Diante da nova ordem mundial, muitos estudiosos afirmam que a distinção entre os níveis de desenvolvimento será em direção de países que possuam ou não informação e, nesse sentido, o ato de abolir barreiras para a troca seria apenas uma das formas de cooperação internacional em busca de uma melhor qualidade de vida.

Todavia, não podemos perder de vista as peculiaridades do grupo social que forma a América Latina. É característica das nações latino-americanas a instabilidade política crônica, prejudicando a sedimentação da cultura democrática e dificultando as reformas sociais. Não basta o bom uso das novas tecnologias, um progresso extraordinário mas insuficiente, necessita-se do domínio da tecnologia para definir qual a sua utilização como instrumento de uma integração efetiva, quer no plano das relações sociais e econômicas quer como liame de uma hegemonia política. A importância do domínio da tecnologia na globalização é destacada por Vigevanni (1997, p.63),

"Trata-se, porém, de ter clara a importância do domínio da tecnologia, pois apenas através dele é possível capacitar-se ao desenvolvimento de produtos necessários para os grupos sociais, as regiões e os países que permanecem tributários de mercadorias necessárias à reprodução de capital, o que consolida fortes desequilíbrios. Não se trata de reinventar a roda, mas de ter em conta que a efetiva adequação ao mundo moderno exige a difusão de conhecimentos e a participação na produção de bens que incorporam tecnologias, portanto de alto valor agregado. A inteligência é a mercadoria melhor remunerada, podendo elevar a qualidade de vida dos povos"

O desenvolvimento de estratégias para otimizar reformas regionais e ações mais efetivas das unidades e sujeitos provedores de informação, no sentido de ampliar e fortalecer o mercado de informação, aprofunda o conceito de desenvolvimento.

Também por aí caminha a oposição entre cidadão e usuário. O cidadão ativo, educado para a tecnologia e para a política, tem que participar da proposição dos projetos políticos e tecnológicos, para não sucumbir aos delírios e à satisfação virtual e momentânea que o "avanço" das novas tecnologias Ihe propicia (o "demasiado virtual"). Esta participação, evidentemente, tem um custo, na medida em que lhe é atribuído um valor, ou melhor, representa o "valor de uso político" inerente às novas tecnologias $^{3}$. Machado (1997, p. 11) ressalta a perspectiva do valor que se encontra em

${ }^{3}$ Para Adam Schaff (em $\boldsymbol{A}$ sociedade informática), a ação que combine conhecimento, tecnologia, política, etc., deve ser orientada pela prática e pela metodologia da Educação Permanente. Segundo Schaff, a Revolução Tecno-científica (engenharia genética, microeletrônica e revolução energética) gera a necessidade de rever os "conteúdos" e as formas tradicionais de produção do conhecimento. 
qualquer projeto, seja político seja tecnológico: "De fato, a construção de projetos não pode prescindir do exame de uma idéia complexa como é a noção de valor. Dissociada de preocupações com valores, a capacidade de projetar pode conduzir a desvios indesejáveis, ou a becos sem saída".

Convênios efetivados entre países signatários e instituições poderão ter um conteúdo mais orgânico, que atenda aos reais interesses e demandas das partes acordadas, uma vez que a instituição biblioteca possui condições de contribuir para a melhor distribuição de direitos e vantagens entre os sujeitos sociais, com a efetiva ação de transferência de conhecimentos. Um homem só é realmente homem quando pode exercer sua faculdade de julgar e realizar escolhas éticas, tanto com relação a seus próprios atos quanto em relação à comunidade em que vive. $E$ assim a cidadania é compreendida como dimensão pública da participação dos homens na vida social e política.

A informação é um direito de todos que pode e deve atuar como fator de integração, democratização, igualdade e dignidade pessoal. Não há exercício de cidadania sem o acesso à informação, isso porque, até para cumprir seus deveres e reivindicar seus direitos, sejam eles civis, políticos ou sociais, o sujeito social precisa conhecer e reconhecê-los, e isso só é possível quando tem acesso à informação.
Uma verdadeira gestão social que permita o desenvolvimento sustentável do bem-estar, a que tem direito o cidadão, é uma meta idealizada por todos os países, mas tem prevalecido a aplicação de políticas de ajustes econômicos, muitas vezes em detrimento de políticas sociais. Na verdade, um lugar, em outro tempo histórico, em que a todo momento muitos falassem sobre a necessidade de desenvolvimento e aplicação de políticas sociais com o objetivo de permitir que as pessoas vivessem melhor, democratizando-se o acesso aos bens culturais, econômicos e sociais. A idéia de rede estaria neste "lugar".

Lojkine, em A revolução informacional (1995, p.17), analisa a produção do conhecimento veiculado e diz que:

"A invenção científica moderna, com efeito, não pode vir à luz e se desenvolver senão por um trabalho de equipe e mediante formas de cooperação que nada têm a ver com a troca de mercadorias entre proprietários privados. A informação assim criada, assentada num trabalho cada vez mais coletivo, não pode ser conservada e, menos ainda, ser enriquecida se for apropriada privadamente: ela perde seu "valor" (de uso), seguindo, nisto, a lei da entropia, se for simplesmente acumulada, estocada como uma mercadoria".

É nesse contexto que se abrem importantes tarefas para as bibliotecas públicas, que sem dúvida alguma devem aban- 
donar seu papel de passividade histórica para assumir um papel transformador, aproveitando a tendência mundial de aplicações de políticas sociais e o papel que a informação passou a ter valor como um recurso econômico e social. Percebemos na atualidade mudanças nas relações de produção, na natureza do Estado, no desenvolvimento de novas tecnologias como fator de mudança nas formas de comunicação, no sistema de informação e no processo de globalização.

Daí que realçamos a necessidade de pontuarmos o "controle social", as "comunidades políticas", a "interação social", o "domínio público" e os "projetos coletivos", em busca da "democracia eletrônica" (tecnodemocracia), superando a mera "democratização eletrônica" (em termos de acesso e consumo), quando da verificação da interação social e da relação de interface com a tecnologia, quando os conteúdos veiculados, impressos ou virtuais, são de domínio público e elaborados de forma democrática. Porque é este sentido propriamente político observado na cidadania ativa, resultante da participação popular e coletiva, que se depreende da análise de Benevides (1991, p. 196-8), quando visualiza o cidadão somente no pleno exercício da política,

"Se assim é, a questão, a meu ver, não se esgota em entender o 'fracasso' - seja técnico, seja político - mas em tentar argumentar pelo lado contrário, ou seja, que os institutos de demo- cracia semidireta contribuem para a educação política do povo (...) Finalmente é bom lembrar que a educação política através da participação em processos decisórios, de interesse público - como em referendos, plebiscitos e iniciativas populares é importante em si, independentemente do resultado do processo. As campanhas que precedem às consultas populares têm uma função informativa e educativa, de valor inegável, tanto para os participantes do lado 'do povo', quanto para os próprios dirigentes e lideranças políticas" (grifos nossos).

O uso de tecnologias passa por aquilo que se pode chamar de "valor político", e com isso a utilização da rede Internet por bibliotecas públicas, como propagadora da informação, desencadeia uma ação de princípios globalizantes, porquanto as transformações informacionais não se reduzem às potencialidades sociais da microeletrônica, mas manifestam-se no conjunto de novas formas de informação, mobilizadas numa relação plural, "radial", que cada vez mais se observa entre os vários segmentos sociais e na produção material da vida. E aqui, portanto, retomamos a importância das bibliotecas como provedoras da informação no momento atual, visto que, se o saber é uma das forças produtivas mais importantes, também o é uma fonte de poder e, por isso, só pode ser visto dentro da idéia de rede e não como se fora uma "rua de mão única". 
Neste período, denominado por muitos de pós-modernidade, temos como características o desenvolvimento de novas formas de tecnologia e informação, a ampliação da difusão da informação e uma mudança nos paradigmas da produção do conhecimento. As transformações com as quais estamos convivendo na realidade contemporânea são evidentes. As atividades e serviços oferecidos mediante o mercado de informações são como alavancas propulsoras da competência e do incentivo para a ampliação ao acesso à informação, nos mais diversos formatos de apresentações, como, por exemplo: sons, imagens, textos, metodologias multimídia. O que facilita a construção e a aplicação do conhecimento nos mais diversos setores sociais e culturais.

É nesse sentido que se pergunta por que a rede é democrática, ou se é democrática. Sem recair na análise maniqueísta de que há boas e más tecnologias, dizemos que a tecnologia é política, tem um "valor de uso político", e que, por isso, a rede, no sentido plural da propagação de informações e formulação de seus próprios conteúdos (nesse caso, parece-nos que educação e comunicação caminham paralelamente) é democrática, ao menos do ponto de vista da pluralidade e de seus princípios globalizantes. Outros elementos consubstanciais à democracia - como o respeito pelas minorias, rotatividade entre os membros formuladores, aceitação das decisões majoritárias e acatamento das "regras do jogo" - ainda esperam ser substantivados (apesar daqueles que alardeiam que não devem ser adjetivados) nas melhores tradições democráticas e nos conteúdos dispostos em rede.

Do ponto de vista dos clássicos, Weber e Marx, a ciência e a tecnologia são tidos como libertadores. Para Weber, tratase do "desencantamento do mundo", do fim das explicações mágicas a respeito da dinâmica natural da vida e, para Marx, é o ensino tecnológico que é libertador. $\mathrm{O}$ que nos permite concluir, sob esta ótica, que a idéia de rede também é democrática - se pensarmos nos clássicos e na era das novas tecnologias.

Aliás, nesse sentido, a utopia de construir uma sociedade socialista no futuro está pautada pela reapropriação coletiva da tecnologia pelos produtores livres. O que demonstra o caráter político que Marx e Engels atribuíram à tecnologia, quando sua reapropriação fosse responsável em grande parte pela reestruturação da vida social. Este aspecto é ressaltado por Nogueira (1993, p.172),

\begin{abstract}
"Além disso, no futuro, quando os trabalhadores se apoderassem da tecnologia, mudanças profundas deveriam ocorrer no âmbito da produção (se não no próprio conteúdo das técnicas, ao menos em seu modo de emprego e na organização do trabalho), o que haveria de acarretar a necessidade de se modificar a relação com o saber e com as instituições encarregadas de
\end{abstract}


transmiti-lo. E essa evolução deveria se dar no sentido do reconhecimento do valor formador do trabalho produtivo, e do estabelecimento de vínculos estreitos entre a instrução e os problemas da produção".

Porém, se a questão tecnológica era enfrentada por Marx e Engels como condição básica para a futura transformação radical das sociedades, ela própria fazia parte de um amplo projeto social e político. $O$ que, em nosso entender, reforça ainda mais a íntima relação entre tecnologia e política. Pois, em última instância, ao nível das transformações sociais, a apropriação política dos conteúdos tecnológicos, por parte dos produtores livres ou das classes trabalhadoras, resultará na reapropriação dos objetivos e fins anteriormente traçados pelo conjunto limitado de tecnólogos e especialistas - o que, por fim, fará com que aflore o conteúdo democrático e progressista que há na condição técnica, quando ela é encarada na perspectiva plural, social, radial, etc. De acordo com Nogueira, em Marx, o acesso à tecnologia é necessário, mas não suficiente (idem, p. 173).

Também o valor de uso político, sob esta análise, é ético, na medida em que sempre se colocam "opções" variáveis e possibilidades de escolha quando há uma relação de princípios democráticos com a tecnologia. Por isso, entendemos que o mesmo núcleo ético das "opções" tecnológicas está presente na própria relação democrática e, no sentido mais geral, também faz parte da relação política ${ }^{4}$, a ponto de se poder escolher entre uma relação política de princípios ou a política de objetivos, de "resultados".

A informação é um recurso econômico, mas com efeito multiplicador muito superior aos outros recursos. É um produto que não se gasta com o uso e pode ser duplicado e transmitido a qualquer parte com custo relativamente baixo, ou seja, um recurso ideal para ser compartilhado.

Verificamos assim a relação estreita entre tecnologia e política e confirmamos que o acesso à tecnologia é um grande passo, mas não o suficiente. Porque, necessita-se da capacitação para a tecnologia, para a busca de informações necessárias com capacidade de análise simbólica em um ambiente em construção.

A Internet estourou os limites da capacidade humana de assimilar os conhecimentos e os acontecimentos mundiais e, ao mesmo tempo, transformou os sujeitos sociais em sujeitos globalizados inseridos em uma "aldeia global".

A informação tornou-se base essencial para o progresso da civilização e da

${ }^{4}$ Nesse sentido, a crítica de Arendt à fragilidade da pseudociência manifesta na mentalidade tecnocrática é muito interessante, porque:

"O problema não é que eles tenham sangue-frio suficiente para 'pensar o impensável', mas o que eles não pensam" (Arendt, 1994, p. 15). É como se a opção possível, inerente ao uso atual da tecnologia, fosse pensar sobre seu "valor político" ou simplesmente se calar diante da "comodidade tecnológica". 
sociedade, é considerada uma matéria-prima para o desenvolvimento e pode ser conceituada como parte da produção de bens, de serviços e de cultura. A ausência de informação e de meios eficazes para o intercâmbio e a disseminação do conhecimento são fatores que limitam o desenvolvimento econômico e social. Vigevanni (1997, p. 64) afirma que,

"Conceituar a informação como parte constitutiva da produção de bens, de serviços e de cultura vincula-se diretamente ao tema da globalização, a qual implica uma nova forma de organização da produção. A globalização traduz-se em melhoria da qualidade dos produtos, rebaixamento dos seus custos e, ao mesmo tempo, sua rápida obsolescência. A reprodução do capital exige prazos cada vez menores, o que torna a informação instantânea um requisito básico da produção e da circulação de valor."

Também se observa uma demanda potencial para a informação, tão volumosa e diversificada que é necessário ampliar os mecanismos de transação que permitam atender a demanda e a oferta.

O uso da rede mundial Internet é uma possibilidade que vai além da integração regional, é uma possibilidade de integração mundial. E em se tratando de países em desenvolvimento a necessidade de integração é questão da própria sobrevivência, pois a utilização da rede como instrumento de integração tem como grande van- tagem a sua característica de compartilhamento de recursos, sistema este que alavancado pela rede das redes pode trazer grandes vantagens para as bibliotecas e comunidades participantes em um grande programa de cooperação.

A utilização da rede Internet é extremamente atraente em razão do volume e variedade de informações que disponibiliza, colocando em prática a idéia de aldeia global apresentada por Marshall McLuhan, e lembrada por Baran (1995, p.41),

"quando Marshall McLuhan, um
dos grandes teóricos da comu-
nicação de massa dos anos 70 ,
formulou o conceito de "aldeia
global" ele, com certeza, não ti-
nha a menor noção do alcance
futuro desse conceito e sua
abrangência. Duas décadas de-
pois, o mundo tem a sua aldeia
global eletrônica onde é possí-
vel interagir e conversar com
pessoas localizadas fisicamente
em outros continentes ou buscar
e recuperar informações situa-
das em locais geograficamente
opostos. Este é o resultado da
explosão da Internet."

A falta de recursos sempre presente nas bibliotecas públicas, a possibilidade de compartilhamento de recursos através da rede Internet e a necessidade de acesso à informação, como sendo a expressão material do conhecimento para que seja utilizado como um instrumento essencial para o desenvolvimento sustentável, é o que nos leva a idealizar um programa de coopera- 
ção entre as bibliotecas públicas com a utilização da rede mundial de telecomunicações Internet. O projeto, no entanto, deve estar estruturado de maneira a concretizar a idéia de Rede dos Cidadãos (Santos e Martinez, 1997), em que se conjugue de forma similar a comunicação, a educação e a interação, num sentido que por ora denominamos de "transdisciplinar" (com conceitos embasados nas três áreas e não simplesmente emprestados e amalgamados por áreas "afins, a exemplo de: rede (tecnologia), politecnia (ensino de pressupostos) e cidadania (resultado da experiência política democrática). O sentido plural é claro em relação às três áreas e aos três conceitos, e podem, portanto, ser conjugados em paralelo, sem prejuízo de um em favor do outro, revelando situações e experiências plurais próprias. Mas ao mesmo tempo semelhantes, se levarmos em conta a experiência da pluralidade que está presente nas três indicações.

Este programa é pautado em um conjunto de ações integrativas em que serão reconhecidas as diferenças e sedimentados os interesses e tarefas comuns e solidárias, possibilitando compreender que, além de globalizada, a sociedade hoje convive com sujeitos cosmopolitas, cidadãos integrados e participativos, uma época de novas oportunidades, novas expectativas, novos negócios, um novo mercado mais expansivo.

Faz-se necessária a concretização de programas dessa natureza, porque hoje nos deparamos com inovações tecnológicas de informação e comunicação que permitem a construção de sistemas estruturados em realidade virtual, e como uma forma de facilitar o acesso à informação, permitindo um grande avanço na realização e nos benefícios dos serviços oferecidos.

Com a evolução de uma economia global, embasada no conhecimento, é necessário que seja fortalecida a competência e a autoridade profissional e institucional dos provedores de informação, a fim de caminharmos por estágios evolutivos. Um primeiro estágio seria o das perturbações causadas pelas tecnologias da informação e da comunicação que exigem mudanças e reestruturações organizacionais. E, o segundo, o das transformações que implicam a exploração intensa dos espaços de atuação tradicionais e principalmente a tentativa de colonizar novas áreas, a exemplo da exploração da rede das redes, em uma proposta de biblioteca cooperativa virtual para o Mercosul.

Ressaltamos que o apelo em favor da cooperação internacional não deve ser encarado como uma coisa utópica, muito menos a possibilidade de implantação de uma biblioteca virtual cooperativa. As condições tecnológicas prévias que permitem a interação de localidades e instituições já existem, o que possibilita mudanças estruturais.

Afinal, temos que considerar que numa era de globalização em que não há Inf.Inf., Londrina, v. 5, n. 2, p. 111-124, jul./dez. 2000 
espaço para o protecionismo à moda antiga, os custos de pesquisa e desenvolvimento freqüentemente ultrapassam a capacidade dos países, individualmente, e que a disponibilização de modernos mecanismos de transação de informação poderão permitir a interligação da capacidade tecnológica, informacional e documentária dos países e das instituições de pesquisa, formando uma rede de cooperação que poderá trazer prosperidade e segurança para a construção de um projeto de intercâmbio bibliográfico e informacional para muitos países, de modo a permitir a possibilidade de transposição das manipulações individualistas, e em prol da realização da interação social.

\section{BIBLIOGRAFIA}

ARENDT, H. A condição humana. Rio de Janeiro : Forense Universitária, 1991.

. Sobre a violência. Rio de Janeiro : Relume-Dumará, 1994.

BARAN, N. O maior espetáculo da Terra. Byte, v. 4, n. 7, p. 48-63, jul. 1995.

BENEVIDES, M. V. M. A cidadania ativa: referendo, plebiscito e iniciativa popular. São Paulo : Ática, 1991.

BOBBIO, N. Liberalismo e democracia. São Paulo : Brasiliense, 1990.

FURNIVAL, A. C. A ciência da informação e o desenvolvimento sustentável. In: SIMPÓSIO INTERNACIONAL PROF. PAULO TARCÍSIO MAYRINK, 2. Marília, 1995.Proceedings... (disquete).
GROVER, M. Proposta para uma política de formação de acervos cooperativos. Cadernos da F. F. C., Marília, v. 4, n. 1, 1995.

LOJKINE, J. A revolução informacional. São Paulo : Cortez, 1995.

MACHADO, N.J. Ensaios transversais: cidadania e educação. São Paulo : Escrituras, 1997.

MARTINEZ, V. C. O cidadão de silício. Marília- SP : UNESP - Faculdade de Filosofia e Ciências, 1997.

MERCIER, P. A., PLASSARD, F., SCARDIGLI, V. La sociedad digital. Barcelona : Ariel, 1985.

NOGUEIRA, M. A. Educação, saber, produção em Marx e Engel. 2.ed. São Paulo : Cortez, 1993.

ROSENFIELD, D. A ética na política: venturas e desventuras brasileiras. São Paulo : Brasiliense, 1992.

SANTOS, P. L. V. A. C., MARTINEZ, V. C. La red ciudadano. In.: CONGRESO INTERNACIONAL DE INFORMACIÓN INFO'97, Havana-Cuba, 1997. Anais... (disquete)

SCHAFF, A. A sociedade informática. São Paulo : Brasiliense, 1992.

VIGEVANNI, T. Globalização e informação: as questões não resolvidas. In: SIMPÓSIO INTERNACIONAL PROF. PAULO TARCÍSIO MAYRINK, 2. Set. 1996, Marília. Anais... Marília : Faculdade de Filosofia e Ciências da UNESP, 1997. p. 61-70. 


\section{Plácida L. V. Amorim da Costa Santos} Professora do Departamento de Biblioteconomia e Documentação da UNESP/Marília;

Coordenadora do Grupo de Pesquisa "Novas Tecnologias em Informação";

Doutora em Semiótica e Lingüística Geral pela USP.

e-mail: gpnti@mii.zaz.com.br

\section{Vinício Carrilho Martinez}

Doutorando pela Faculdade de Educação da Universidade de São Paulo (FEUSP); Mestre em Educação pela UNESP-Marília; Bacharel em Direito e Ciências Sociais. e-mail: gpnti@mii.zaz.com.br

\section{Title}

The Net and the Knowledge

\section{Abstract}

In the future, with the increasing virtualization (technology replacing the public space in the political practice), it shall be known if democracy has been put on the (public) net or if it has only been "technologized" having become the most expensive image of the concept, namely, "publicity". The articulation of the idea of net with the experience of public libraries would be a possibility in the carrying out of social interaction as well as in the building of citizenship.

\section{Keywords}

Democracy; Net; Information; Public Libraries.

\section{Titulo}

La Red y el Conocimiento

\section{Resumen}

En el futuro, con la creciente virtualización ( tecnología sustituyendo el espacio público de la práctica política ), es donde se mostrará si la democracia fue puesta en red ( pública) o si simplemente fue "tecnologizada", convirtiéndose en la imagen más cara del concepto, o sea , "publicidad". La articulación de la idea de red con la experiencia de las bibliotecas públicas sería una posibilidad en la realización de la interacción social y en la construcción de la ciudadanía.

\section{Palabras-Clave}

Democracia; Red; Información; Bibliotecas Públicas.

Artigo recebido em: 30/04/98 